\title{
To Assess the Effect of Breast Feeding Self Efficacy Intervention on Primiparous Mothers
}

\author{
Kavita J. Gomase ${ }^{1}$, Pooja Kasturkar², Bali Thool ${ }^{1}$ and Archana Teltumbde ${ }^{1}$ \\ ${ }^{1}$ Department of Obstetrics and Gynaecology Nursing,, Smt. Radhikabai Meghe \\ Memorial College of Nursing, Datta Meghe Institute of Medical Sciences, \\ (Deemed to be University), Sawangi Meghe, Wardha, Maharashtra, India. \\ ${ }^{2}$ Department of Mental Health Nursing, Smt. Radhikabai Meghe Memorial College of \\ Nursing, Datta Meghe Institute of Medical Sciences, (Deemed to be University), \\ Sawangi Meghe, Wardha, Maharashtra, India.
}

\section{ABSTRACT}

Breastfeeding is long recognized as a popular form of feeding during the first year of life (American Academy of Pediatrics, 1997). Despite the obvious benefits of breastfeeding to mother and child, breastfeeding rates in many parts of the world and in India tend to stay below the recommended levels..There have been many research studies in which trust in breast feeding has been shown to be an important factor in early initiation, productive establishment and continued breastfeeding. A longitudinal retrospective analysis of 64 low-income mothers in the United States reveals that trust in breastfeeding is correlated with early termination of breastfeeding rather than perceived problems. Methods and Material: This study was based on the application of Pre experimental-One Group Pre post test design. This study includes 60 samples. Used for purpose sampling technique. A tool is a data collection tool or equipment used by Breast Feeding Self - Efficacy Scale. There have been two sections that are primigravida woman's demographic information and breast feeding self - EfEfficacy Scale. Results There is a significant difference between pretest scores and posttest knowledge scores that interpret effective breast feeding self-efficacy breastfeeding intervention. The mean pretest value is 95.83 and the posttest value is 129.80 , and the standard pretest deviation value is 30.032 and the posttest value is 20.419. Conclusion: T-value is calculated at 8.502 and p-value is 0.000 . Therefore it is interpreted statistically that breast feeding self-efficacy intervention on breastfeeding has been successful.

KEY WORDS: IMPACT, BREASTFEEDING SELF-EFFICACY BREASTFEEDING INTERVENTION, MOTHERS PRIMIPAROUS.

\section{INTRODUCTION}

Lactation facilitated human survival. Breastfeeding infants abstain nutritional, immunological, cognitive and psychosocial advantages. Human milk contains both

\section{ARTICLE INFORMATION}

*Corresponding author email: kavitapravin3@gmail.com Received 12th Oct 2020 Accepted after revision 29th Dec 2020 Print ISSN: 0974-6455 Online ISSN: 2321-4007 CODEN: BBRCBA

Thomson Reuters ISI Web of Science Clarivate Analytics USA and Crossref Indexed Journal

\section{Clarivate
Analytics}

NAAS Journal Score 2020 (4.31)

A Society of Science and Nature Publication, Bhopal India 2020. All rights reserved.

Online Contents Available at: http//www.bbrc.in/

Doi: http://dx.doi.org/10.21786/bbrc/13.15/54 biochemistry as well as biology. It have effective features that have provided evidence of the nutritional benefits of breastfeeding. Although, the contents of breast milk is varied from mother's milk to other mammals. Proteins, fat, carbohydrates, vitamins, and minerals in mother's milk also different from the milk of other mammals. The composition of substitute milk is the identical, but the composition of mother's milk will be altered.

If there were evidence means associated with the further benefits of breast feeding help to minimize child morbidity, cost of health care and initiation. But breastfeeding in primipara mothers is difficult to sustain, and it is more common among low-income women.It is 
not easy to learn the art of breastfeeding. The climate of society in past century for breastfeeding has been irregular that results introduction of breastfeeding may experience without any social support. That will cause premature termination of breastfeeding. Although health care professionals may positively encourage women for breastfeeding.

They have been reported as lack of knowledge, not helpful ,sending inaccurate information and being inconsistent in their treatment and counselling about breastfeeding to the women. (Anderson \& Geden, 1991; Hayes, 1981; Humenick et al. 1998). Teaching and support about breastfeeding by nursing personnel have been reported to enhance breastfeeding success 2 India is home to maximum number of under five deaths(21\%of the global burden) and $1 / 3$ of the world' s underweight children under the age of five years. Early breast feeding within one hour of life and exclusive breast feeding during the first six months are key interventions to reduce child malnutrition and mortality 3 In India, women who initiate breast feeding within one hour of delivery are only $24.5 \%$, whereas the exclusive breast feeding rates for children under six months are only 46.4\%. Given the policies and services that Rule has implementedit has seen that initiation of breast feeding has increased just about 1\% each year and exclusive breast feeding has in fact declined3.

A pilot randomized controlled trial of a breast feeding self effectiveness intervention with 150 primiparous mothers conducted in Ontario, Canada in 2008. The intervention group received three individualized sessions which strengthened self-efficacy. At 4weeks Postpartum the intervention group mothers had a higher mean of BFSE-SF ( $M=58.4, S D=11$ vs. $M=54.0, S D=14)$. Only 14 percent of mothers discontinued breastfeeding in the intervention group at 4 weeks postpartum compared to 26 percent in the control group and the intervention group was more exclusive (61 percent) than those in the control group4 A 2007 study at NEW SOUTH WALES, Australia, pointed to a increase among 90 percent females in breast-feeding self-efficacy and real breast-feeding through and practice.

Women who have been educated in breast-feeding self-efficacy showed significantly greater increases in breast-feeding self-efficacy, a trend towards breastfeeding of their infants longer and more exclusively than those in charge in the control group 5 A descriptive research is seen in 2007 to investigate the influences of efficacy-enhancing experiences among 63 mothers on breast-feeding self-efficacy. The impacts of vicarious verbal reference and physiological forms of experience on breast feeding self-efficacy are analyzed at 48 hours and 4 weeks postpartum using the Scale-Short Form breastfeeding auto-efficacy.The data suggest that the mothers who received intervention had significantly greater percentages of self-efficacy in breastfeeding than those who did not receive6
A 2006 research conducted among 110 primiparous mothers in the US to assess the effects of prenatal breast feeding workshop on self-efficacy of maternal breast feeding and breastfeeding duration. Results in the control group scores at the fourth postpartum weeks were slightly lower than in the intervention groupThere was a higher rate of exclusive breast feeding in the intervention group at the eighth week postpartum mothers (70\%) than the control group (57\%)7.

A survey was followed to determine the effect on breastfeeding results of mothers receiving health promotion material and education from among 587 mothers in Western Australia. Study revealed that moms with hospital staff receiving antenatal breastfeeding education were less willing to stop full breastfeeding before six months (55 per cent). For mothers seeking medical treatment (30\%) For (30\%) mothers seeking medical care during the postnatal period, breastfeeding was less likely to stop before six months8.

All of these reasons specifically state the need for a breastfeeding program to strengthen self-efficacy. Midwives may alter the morale of a mother in breastfeeding as the belief focuses exclusively on the skills and ability they achieve and the encouragement. Breast feeding self - Effectiveness Enhancing program composing information on the importance of breast feeding for mothers and babies, exclusive breast feeding, breast feeding techniques such as proper latching, baby positioning and handling, how to overcome physiological problems and stress, psychological support, affirmation and motivation will help primary mothers develop initial caffirmation and motivation will help the primi mother develop initial confidence and achieve good breast feeding. Even though the confidence formation is a long term process, the investigator aims to give an initial boost through this intervention which enhances her confidence and thus helps her to sustain in exclusive breast feeding.

\section{Objectives}

1. To assess the self-efficacy of breastfeeding in primiparous mother by using a self-efficacy scale for breast feeding.

2. To evaluate the self-efficacy of breastfeeding in primiparous mother by using a self-efficacy scale of breast feeding.

\section{Assumptions}

1. To determine the self-efficacy of breastfeeding in primiparous mother by using a self-efficacy scale for breast feeding.

2. Development of initial confidence will help mothers to establish successful breast feeding.

\section{Hypotheses}

H1. The mean post-test score on Breast Feeding SelfEfficacy will be significantly higher than the mean pre-test score 


\section{MATERIAL AND METHODS}

This study was based on Pre experimental - One Group Pre test post test design is used. Population refers to primiparous antenatal women who are admitted for parturition and the same primiparous mothers at immediate postnatal period who gave birth to a single, during their hospitalization In this study, 60 sample are included.

\section{Inclusion Criteria}

1. Primiparous antenatal women who are admitted for delivery

2. Primiparous mothers who delivered a single healthy baby and are within first 12 hours of post partum period and who were assessed prior to the delivery for self efficacy.

3. Primiparous mothers who are able to breast feed their baby.

\section{Exclusion Criteria}

1. Moms that have some disorder that can greatly interfere with breast feeding, such as serious disease, and a congenital defect or child admitted to NICU.

2. Multiparous mothers.

3. Mothers with Caesarean Section

Development of tools: A tool is an instrument or equipment use for collection of data which is Breast Feeding Self -Efficacy Scale

Section I- Demographic information of primigravida woman.

\section{Section II- Breast Feeding Self -Efficacy Scale}

Data Collection Method: 1. Moms that have some disorder that can greatly interfere with breast feeding, such as serious disease, and a congenital defect or child admitted to NICU. An interview schedule will be used to elicit the Demographic Profile. After delivery those who are fulfilling the eligibility criteria will again assessed with the same BFSES. Those who are found with low breast feeding self - efficacy, will receive individualized Breast Feeding Self- Efficacy Intervention on the first day of post partum. Breast feeding by the mother from the initial stage of placement of baby on breast till the feeding is over, will be observed from a far .This observation will be made three times a day (9am-5pm) for three consecutive days and followed by it, mother will be interviewed to assess breast feeding self-efficacy. Post test will be conducted on fourth day, using the same Breast Feeding Self -Efficacy Scale. Participants will be thanked for their co-operation.

RESULTS

Section I- Percentage wise distribution of primiparous mother with regards to selected demographic variables
SECTION-II: Assessment the breast feeding self-efficacy in primiparous mothers by using a breast feeding self -efficacy scale

Table 1. Percentage wise distribution of Women with regards to selected demographic variables. $\mathrm{n}=60$

\begin{tabular}{|c|c|c|}
\hline Demographic variable & Frequency & Percentage $(\%)$ \\
\hline \multicolumn{3}{|l|}{ Age(years) } \\
\hline $18-21$ & 15 & 25 \\
\hline $22-25$ & 29 & 48.33 \\
\hline $26-29$ & 11 & 18.33 \\
\hline $30-33$ & 4 & 6.6 \\
\hline Above 34 & 1 & 1.6 \\
\hline \multicolumn{3}{|l|}{ Weeks of pregnancy } \\
\hline$<30$ weeks & 1 & 1.6 \\
\hline 31-33 weeks & 12 & 20 \\
\hline 34- 36 weeks & 45 & 75 \\
\hline$>37$ weeks & 2 & 3.3 \\
\hline \multicolumn{3}{|l|}{ Religion } \\
\hline Hindu & 36 & 60 \\
\hline Muslim & 6 & 10 \\
\hline Christian & 5 & 8.3 \\
\hline Others & 13 & 21.66 \\
\hline \multicolumn{3}{|l|}{ Education of women } \\
\hline Primary & 5 & 8.3 \\
\hline Secondary & 40 & 66.66 \\
\hline College degree & 15 & 25 \\
\hline Post graduation and above & 00 & 00 \\
\hline \multicolumn{3}{|l|}{ Occupation of women } \\
\hline Private & 7 & 11.66 \\
\hline Government & 5 & 8.33 \\
\hline Farmer & 5 & 8.33 \\
\hline Housewife & 43 & 71.66 \\
\hline \multicolumn{3}{|l|}{ Duration of marriage life } \\
\hline 1-2 years & 43 & 71.66 \\
\hline 3-4years & 8 & 13.33 \\
\hline 5-6 years & 2 & 3.33 \\
\hline 7-8 years & 7 & 11.66 \\
\hline \multicolumn{3}{|l|}{ Family income } \\
\hline Less than Rs. 3000/- & 6 & 10 \\
\hline Rs. 3001-5000/- & 15 & 25 \\
\hline Rs. 5001-7000/- & 19 & 31.66 \\
\hline More than Rs.7000/- & 20 & 33.33 \\
\hline \multicolumn{3}{|l|}{ Type of family } \\
\hline Nuclear family & 37 & 61.66 \\
\hline Joint family & 23 & 38.33 \\
\hline \multicolumn{3}{|l|}{ Residence } \\
\hline Urban & 44 & 73.33 \\
\hline Rural & 16 & 26.66 \\
\hline
\end{tabular}

- Table no.4 shows that primiparous mother 3(5\%) had not confident at all, 42(70\%) of them had half the time confident, $6(10 \%)$ of them had usually confident, and 9(15\%) had always confident. The 
minimum score was 2 and the maximum score was 152 , the mean score was $95.83 \pm 30.032$ with a mean percentage score of 58.07.

\section{PART B}

Assessment of post test score of the breast feeding selfefficacy in primiparous mothers by using a breast feeding self -efficacy scale.

Table no. shows that $4(6.6 \%)$ had half the time confident, $31(51.66 \%)$ had usually confident and 25(41.66\%) had always confident. The minimum score was 92 and the maximum score was 156 , the mean score was $129.80 \pm$ 20.419 with a mean percentage score of 78.66 .

SECTION-III: Effectiveness of breast feeding self-efficacy intervention on breastfeeding among primiparous mothers by comparing pre-test and post-test scores

Table no.6 confirms that there is a huge disparity between pretest scores and posttest learning scores that define positive breast feeding self-efficacy in breastfeeding intervention. The breast feeding self efficacy intervention on breastfeeding was effective. Thus the H1 is accepted.

Table 2. Assessment the breast feeding self-efficacy in primiparous mothers by using a breastfeeding self-efficacyscale.

\begin{tabular}{|l|c|c|c|c|}
\hline \multirow{2}{*}{$\begin{array}{l}\text { Breastfeeding self- } \\
\text { efficacy score }\end{array}$} & Score range & Percentage score & \multicolumn{2}{|c|}{ Pre Test } \\
\cline { 4 - 5 } & & & Frequency & Percentage \\
\hline Not confident at all & $0-33$ & $0-20 \%$ & 3 & $5 \%$ \\
\hline Not very confident & $34-66$ & $21-40 \%$ & 0 & $0 \%$ \\
\hline Half the time confident & $67-99$ & $41-60 \%$ & 42 & $70 \%$ \\
\hline Usually confident & $100-132$ & $61-80 \%$ & 6 & $10 \%$ \\
\hline Always confident & $133-165$ & $81-100 \%$ & 9 & $15 \%$ \\
\hline Minimum score & 2 & & & \\
\hline Maximum score & 152 & & & \\
\hline Mean score & $95.83 \pm 30.032$ & & & \\
\hline Mean \% & $58.07 \%$ & & & \\
\end{tabular}

Table 3. Assessment of post test score of the breast feeding self-efficacy in primiparous mothers. $n=60$

\begin{tabular}{l|c|c|c|c|}
\hline \multirow{2}{*}{$\begin{array}{l}\text { Breastfeeding self- } \\
\text { efficacy score }\end{array}$} & Score range & \multirow{2}{*}{ Percentage score } & \multicolumn{2}{|c|}{ Post Test } \\
\cline { 4 - 5 } & & & Frequency & Percentage \\
\cline { 1 - 1 } Not confident at all & $0-33$ & $0-20 \%$ & 0 & $0 \%$ \\
\hline Not very confident & $34-66$ & $21-40 \%$ & 0 & $0 \%$ \\
\hline Half the time confident & $67-99$ & $41-60 \%$ & 4 & $6.66 \%$ \\
\hline Usually confident & $100-132$ & $61-80 \%$ & 31 & $51.66 \%$ \\
\hline Always confident & $133-165$ & $81-100 \%$ & 25 & $41.66 \%$ \\
\hline Minimum score & 92 & & & \\
\cline { 1 - 2 } Maximum score & 156 & & & \\
\cline { 1 - 2 } Mean score & $129.80 \pm 20.419$ & & & \\
\hline Mean $\%$ & $78.66 \%$ & & & \\
\end{tabular}

Table 4. Percentage wise distribution of Effectiveness of breast feeding self-efficacy intervention on breastfeeding among primiparous mothers by comparing pre-test and post-test scores $n=60$

\begin{tabular}{|l|c|c|c|c|c|c|}
\hline Tests & Mean & SD & 't'-value & $\begin{array}{l}\text { Degree of } \\
\text { Freedom }\end{array}$ & p-value & Significant \\
\hline Pre Test & 95.83 & 30.032 & 5.502 & 59 & 0.000 & S, p < 0.05 \\
Post Test & 129.80 & 20.419 & & & & \\
\hline
\end{tabular}




\section{DISCUSSION}

A cross-sectional survey in Guangzhou, China shows that a total 640 qualified women have been come up to and 571 moms have finalized the education with an 86 percent reaction rate. In the immediate postpartum period, mums showed moderate degree of self-efficacy in breast feeding. The best-fit regression study identified six variables that clarified 43.9 per cent of the variance in self-efficacy of breast feeding in the immediate postpartum period. The aim was to feed the breast, support the mother, support the nurses / midwives, attend prenatal breast feeding courses, period from birth to breast feeding and previous breastfeeding experience9.

A longitudinal study was designed to examine the effectiveness of a self-efficacy-centered breast feeding education program (SEBEP) in boosting breast feeding self-efficacy, breast feeding time and exclusive breast feeding outcomes among mothers in Hong Kong. Analytical tests based on an intention-to-treat (ITT) assumption showed a substantial difference $(\mathrm{p}<0.01)$ in the shift in mean BSES-SF scores between the mothers who received SEBEP and those who did not receive SEBEP at two weeks post partum.

The exclusive breast feeding rate in the intervention group was 11.4 percent and the control group at six months post partum was 5.6 percent. The findings of this study highlight the feasibility of a major breastfeeding trial in Hong Kong with the goal of the self-efficacy and exclusive breast feeding rates $10 \mathrm{~A}$ total of 85 low birth weight babies and their mothers who had received care in the two hospitals' neonatal clinics. In the first 5 days of their hospitalization the mothers included in the study group were given breast-feeding supervision in half an hour a day. Home visits were decided to carry out in the study and control classes at the participants' homes before the children reached the age of 6 months.

The following methods were used for collecting data: Personal Data Form, Breast-feeding Self-Efficacy Form, LATCH Breast-feeding Evaluation Method, and Form for anthropometric data. Researchers used t-tests to evaluate the data obtained, rate, arithmetic mean, standard deviation, and chi-square in separate classes. Findings: Natural-food education provided to the mothers has been determined to improve their breast-feeding self-efficacy and breast-feeding success $(\mathrm{P}<0.05)$. This was found that in the study group, in contrast with the control group $(\mathrm{P}<0.001)$ The rate of feeding the children exclusively with breast milk is greater 11 The results to present the analysis are described above. The research in this area has been examined which has a direct or indirect impact on the efficacy of breast feeding 12-13.

\section{Nursing Implication}

Nursing services:- Nurses employed in the existing obstetrics will benefit from these studies, as this form of breast feeding self-efficacy interventions would provide in the setup of obstetrics.
Nursing administration:- Administrative personnel, hospital workers should provide a clear contact network to receive information on breastfeeding self-efficacy intervention.

Nursing education: Nursing education is developing in India and nurses from our country can be found throughout the world providing education. Nursing education should help that include value and sense of responsibility in students to educate breastfeeding selfefficacy

\section{Recommendations}

- A similar study may be conducted or a larger population for generalization of findings

- A comparative study on Breastfeeding Self-Efficacy Intervention on breastfeeding between working and non-working primiparous women.

\section{CONCLUSION}

The finding indicates that breastfeeding self-efficacy intervention on breastfeeding is very effective in increasing the efficacy of breast feeding which is an important primiparous female factor. It also increases breast feeding time.

\section{REFERENCES}

Bernaix, L.W., Schmidt, C.A., Arrizola, M., Iovinelli, D. and Medina-Poelinez, C., 2008. Success of a lactation education program on NICU nurses' knowledge and attitudes. Journal of Obstetric, Gynecologic \& Neonatal Nursing, 37(4), pp.436-445.

Chan, M.Y., Ip, W.Y. and Choi, K.C., 2016. The effect of a self-efficacy-based educational programme on maternal breast feeding self-efficacy, breast feeding duration and exclusive breast feeding rates: a longitudinal study. Midwifery, 36, pp.92-98.

Gawai, J. and Tendolkar, V., 2019. Perception of mental health problems and coping strategies among rural women living in vidarbha region. Journal of Datta Meghe Institute of Medical Sciences University, 14(3), p.215.

Ghasemi, V., Simbar, M., Ghasemi, E., Ebadi, A., Kiani, Z., Mahdizad Keyghobad, F. and Haghi Navand, P., 2019. Predictor Factors of Breastfeeding Attitude in Iranian Breastfeeding Mothers: A Cross-Sectional Study. International Journal of Pediatrics, 7(3), pp.91039113.

Küçükoglu, S. and Çelebioglu, A., 2014. Effect of natural-feeding education on successful exclusive breast-feeding and breast-feeding self-efficacy of lowbirth-weight infants. Iranian Journal of Pediatrics, 24(1), p.49.

Madhu, K., Chowdary, S. and Masthi, R., 2009. Breast feeding practices and newborn care in rural areas: a descriptive cross-sectional study. Indian journal of 
community medicine: official publication of Indian Association of Preventive \& Social Medicine, 34(3), p.243.

McCarter-Spaulding, D.E. and Kearney, M.H., 2001. Parenting self-efficacy and perception of insufficient breast milk. Journal of Obstetric, Gynecologic, \& Neonatal Nursing, 30(5), pp.515-522.

McQueen, K.A., Dennis, C.L., Stremler, R. and Norman, C.D., 2011. A pilot randomized controlled trial of a breastfeeding self-efficacy intervention with primiparous mothers. Journal of Obstetric, Gynecologic et Neonatal Nursing, 40(1), pp.35-46.

Nichols, J., Schutte, N.S., Brown, R.F., Dennis, C.L. and Price, I., 2009. The impact of a self-efficacy intervention on short-term breast-feeding outcomes. Health Education \&t Behavior, 36(2), pp.250-258.

Noel-Weiss, J., Rupp, A., Cragg, B., Bassett, V. and Woodend, A.K., 2006. Randomized controlled trial to determine effects of prenatal breastfeeding workshop on maternal breastfeeding self-efficacy and breastfeeding duration. Journal of Obstetric, Gynecologic \& Neonatal Nursing, 35(5), pp.616-624.

Pannu, P.K., Giglia, R.C., Binns, C.W., Scott, J.A. and Oddy, W.H., 2011. The effectiveness of health promotion materials and activities on breastfeeding outcomes. Acta Paediatrica, 100(4), pp.534-537.

Shrivastava, D. and Master, A., 2020. Fetal Growth Restriction. The Journal of Obstetrics and Gynecology of India, 70(2), pp.103-110. 